\title{
Dimensionality of narcissism: a Bifactorial model of the Narcissistic Personality Inventory using single-stimulus response formats
}

\author{
Márton Engyel ${ }^{1,2} \cdot$ Róbert Urbán $^{2}$ • Szabolcs Bandi ${ }^{3,4}$ • László Nagy ${ }^{3,4}$ \\ Published online: 4 August 2020 \\ (C) The Author(s) 2020
}

\begin{abstract}
The Narcissistic Personality Inventory is a widely used measure of narcissism; however, several different conflicting factor structures have been proposed. The present study aimed to untangle those differences by offering a bifactor model of narcissism with an underlying general narcissism factor and several specific factors. Our objective was to estimate the variance explained by the general and the specific factors. Therefore, we applied a set of confirmatory factor analyses on three independent studies $(N=$ $791 ; N=319$ and $N=237$ ), and also tested the construct validity of these factors with other contemporary measures of grandiose and vulnerable narcissism, big five personality traits, explicit self-esteem, gender and well-being. Our results suggest that the bifactor model with three specific factors yielded acceptable fit to our data in all of the different single-stimulus response formats and languages used in our studies and modelling three specific factors offered more insight into the adaptive and maladaptive characteristics of narcissism. The general narcissism factor alone explains only about half of the common variance, highlighting the importance of the specific factors as well.
\end{abstract}

Keywords Grandiose narcissism $\cdot$ Confirmatory factor analysis $\cdot$ Construct validity $\cdot$ Bifactor model

\section{Introduction}

Narcissism and narcissistic traits are Janus-faced qualities: on the one hand, they are associated with personal benefits to the narcissistic individual but, on the other, they may present a burden to other people, family and society (Twenge et al. 2008). Narcissism is originally a psychoanalytically-oriented construct (Ronningstan 2013); however, it has a robust impact on almost every field of psychology (Campbell and Miller

Electronic supplementary material The online version of this article (https://doi.org/10.1007/s12144-020-00971-2) contains supplementary material, which is available to authorized users.

Márton Engyel

engyel.marton@ppk.elte.hu

1 Doctoral School of Psychology, ELTE Eötvös Loránd University, Budapest, Hungary

2 Institute of Psychology, ELTE Eötvös Loránd University, Budapest, Hungary

3 Department of Personality and Health Psychology, Institute of Psychology, Faculty of Humanities, University of Pécs, Pécs, Hungary

4 Psychopathology Research Group, Faculty of Humanities, University of Pécs, Pécs, Hungary
2012). With the development of empirically-based scientific methods and psychological measurements, the emphasis gradually transferred from clinical case studies to the trait-based, personality psychological approaches. However, several projective techniques have their own narcissism indices (Bandi et al. 2017) the most popular independent forms of the assessment of narcissism are self-report scales. Despite the common critiques related to the problem of social desirability in the assessment of maladaptive subclinical personality traits, numerous self-report narcissism tests have emerged (Emmons 1987).

According to the widely accepted approach, two major forms of narcissism can be differentiated: grandiose narcissism and vulnerable narcissism (Pincus and Lukowitsky 2010), and assessment of narcissism generally focuses on one or the other (Hendin and Cheek 1997; Cheek et al. 2013). Individuals with grandiose narcissistic traits are described as arrogant, exploitative and entitled, while their self-esteem regulation is mainly characterised by selfaggrandisement and devaluation of others (Zeigler-Hill et al. 2008). Vulnerable narcissistic people, in contrast, are selfinhibited and rely heavily on the approval of others (Cooper and Maxwell 1995; Zeigler-Hill et al. 2008), but they also have grandiose expectations of themselves and others (Kealy and Rasmussen 2012; Wink 1996). 
Narcissism viewed as a set of traits however is limiting our understanding of the role of normal narcissistic personality functioning. It offers limited help in explaining why these exact traits form narcissism and what can be in the core of these different narcissistic tendencies. To deal with this gap recent models of narcissism are beginning to conceptualise narcissism as a dynamic self-regulatory process (Giacomin 2016) in which all narcissistic behaviours are serving the aim of maintaining a positive self-view (Morf and Rhodewalt 2001; for a review, see Giacomin 2016).

Several contemporary measures exist to assess both vulnerable and grandiose narcissistic traits together (eg. the FiveFactor Narcissism Inventory (FFNI; Glover et al. 2012), the Pathological Narcissism Inventory (PNI; Pincus et al. 2009), but the most widespread measure of narcissistic grandiosity is still the Narcissistic Personality Inventory (NPI; Raskin and Terry 1988; Cain et al. 2008). Although this scale is widely used, its internal measurement model is still not clear, and different factor structures have been proposed (Fig. 1). Raskin and Terry (1988) originally identified seven principal components: Authority, Exhibitionism, Superiority, Entitlement, Exploitativeness, Self-Sufficiency and Vanity.
The large correlations among the primary factors implied a secondary general factor, though it was not tested (Raskin and Terry 1988). Corry et al. (2008) offered a two-factor solution with only Leadership/Authority and Exhibitionism/ Entitlement factors; however, these factor structures could not be confirmed in independent confirmatory research (Ackerman et al. 2011). Ackerman et al. (2011) proposed a three-factor solution distinguishing the adaptive Leadership/ Authority ( $L / A)$ factor from the maladaptive Grandiose Exhibitionism (GE) and Entitlement/Exploitativeness (E/E) factors. One of the greatest advantages of the results from Ackerman and colleagues' work (2011) is the appearance of the possible social adaptational value of narcissistic tendencies, which is consonant with current interest around the construct of 'healthy' narcissism (Solan 2015). Nevertheless, the confirmation of this three-factor solution in independent samples is necessary to accept it as a measurement model.

Previous research mainly tested models with primary factors, though to understand the possible uni- or multidimensionality of narcissistic personality inventory hierarchical models within a confirmatory factor analysis framework should be considered. If we view narcissism as a dynamic

Fig. 1 Model 8

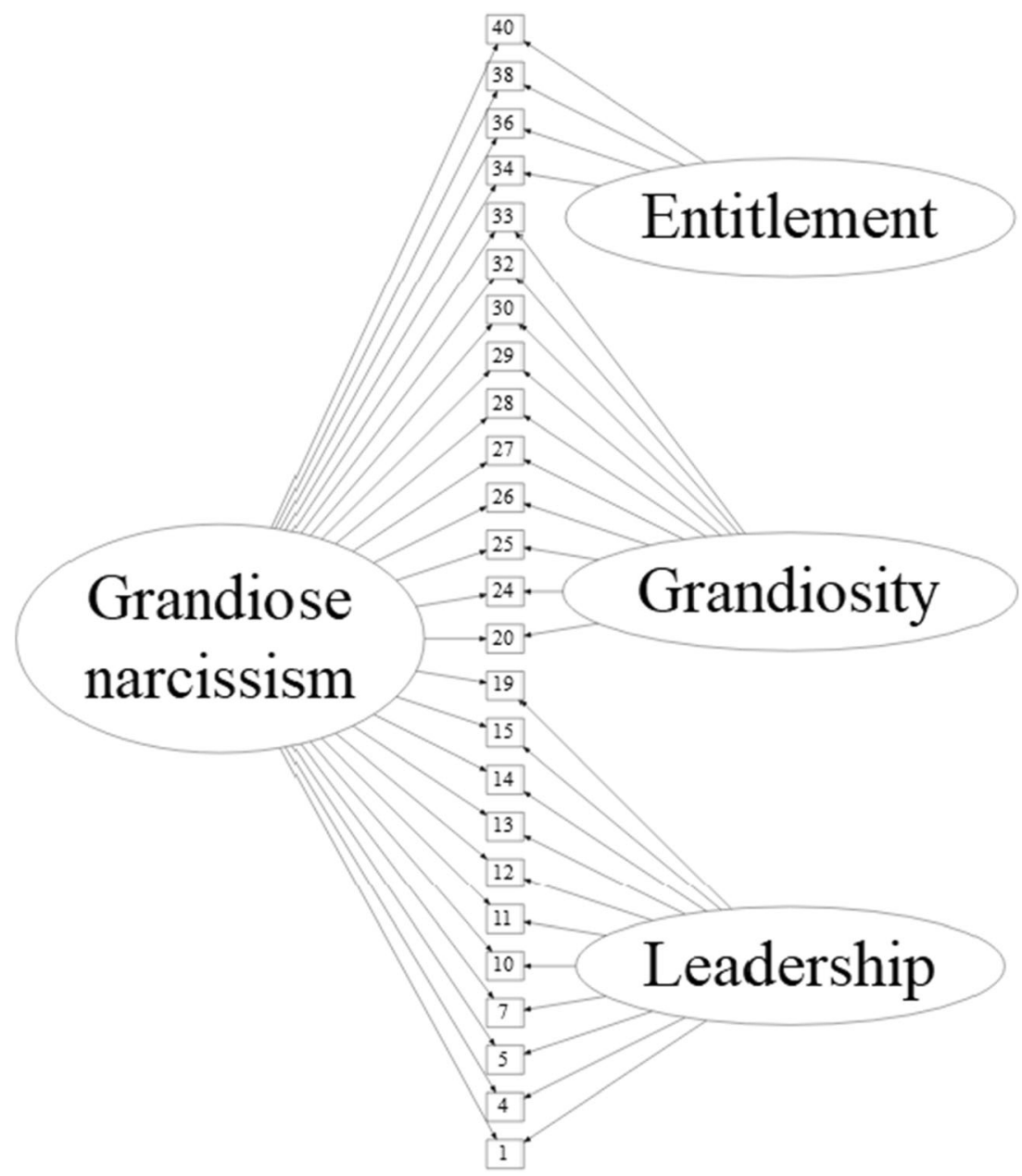


self-regulatory process, all narcissistic traits or behaviours should have a common underlying aim of maintaining a positive self-view, questioning the dimensionality of the constructs used. It is of increasing interest to apply both secondorder and bifactor models in personality research (Reise 2012), in order to clarify the dimensionality questions of a given construct. In second-order models, the higher order factors are said to explain the correlation between the primary factors, while the bifactor model approach aims to differentiate the amount of variance explained by a single general factor and specific relevant factors. The other advantage of the bifactor approach is that specific and general factor's relationship with external variables can be captured separately (Reise et al. 2010). Moreover, recent studies suggested that bifactor models can be applied to general psychopathology as well (the " $p$ " factor) supporting a transdiagnostic approach (Caspi et al. 2014), and this general factor is stable over time, and describes temporal changes in psychopathology well (Gluschkoff, Jokela and Rosenström 2019).

As there was no clear agreement on the different factor structures, and higher order factor models were not or rarely tested previously, the first aim of our two studies was to compare the competing measurement models with a series of confirmatory factor analyses (CFA) to identify the best fitting solution to our data collected with both the Hungarian and English versions of the NPI. The second aim was to test the concurrent validity and associations of the best fitting model in two sets of confirmatory factor analysis models with covariates including self-esteem, other measures of vulnerable and grandiose narcissistic traits and well-being measures.

Grandiose narcissism and explicit self-esteem are constantly found to be positively correlated (Hyatt et al. 2018; Campbell et al. 2002; Kernis and Sun 1994), because both constructs capture positive perceptions of the self and are positively related to agentic traits, however the difference lies between their association to communal traits (Hyatt et al. 2018). Out of the subscales of NPI, Entitlement/ Exploitativeness has the strongest negative associations with communal traits (Pryor et al. 2008), while Leadership/ Authority and Grandiose Exhibitionism are positively associated with agentic traits (Gentile et al. 2013). Therefore, selfesteem seems to be an appropriate construct to test the construct validity of the NPI. Moreover, if we consider narcissism as a self-regulatory process for maintaining positive selfviews we can expect a positive relationship between explicit self-esteem and grandiose narcissism in general.

Furthermore, there is a growing interest in differentiating the adaptive and maladaptive sides of narcissism (for a review see Cai and Luo 2018; Rose 2002); therefore, eudaimonic well-being, as in living a complete, authentic, self-directed life with satisfying relationships (Ryff and Keyes 1995), seems to be another useful construct with which to test this construct. Previous research showed that narcissism is positively related to greater eudaimonic and hedonic well-being especially when controlled for other dark triad traits (Aghababaie and Blachnio 2015) and this relationship is mediated through self-esteem (Zuckerman and O'Loughlin 2009); we thus expect positive relationships with both self-esteem and eudaimonic wellbeing.

Lastly, the differentiation between vulnerable and grandiose narcissistic traits also presents a useful opportunity to test discriminant validity, as previously no significant relationship was found between grandiose and vulnerable narcissism using the NPI (Miller et al. 2018; Cheek et al. 2013; Hendin and Cheek 1997). Only Entitlement/Exploitativeness subscale have shown a positive association with measures of vulnerable narcissism in previous studies (e.g. Crowe et al. 2018a and b; Krusemark et al. 2018).

Therefore, the aim of this paper is to enable the differentiation of the variance between the general narcissism factor and the specific factors offered by previous research - measured in the single-stimulus format of the NPI.

In Study 1 we tested the different measurement models and the association of those with covariates on a large sample $(N=$ 791) using the Hungarian version of the NPI, while in Study 2 we tested the associations of the best-fitting model with other contemporary measures of vulnerable and grandiose narcissism with the English version of the NPI $(N=319)$. To assess measurement invariance between the Hungarian and English versions of the NPI, and to provide further evaluation of the bifactor model across different response formats we also conducted a third study (Study $3 ; N=237$ ).

\section{Study 1}

\section{Methods}

\section{Participants and Procedure}

We pooled three convenience samples in the current study. Participants in the first sample (Sample 1) were 226 university students $(76.5 \%$ women, mean age $=21.17 ; \mathrm{SD}=2.57)$ from a large university in Budapest; for the second (Sample 2; $n=$ 414) and third samples (Sample 3; $n=152$ ) 566 university students $(76.9 \%$ women, mean age $=27.29 ; \mathrm{SD}=10.95)$ were recruited from a university in Pécs. As more samples were pooled in Study 1, ethical approvals were granted in both universities for conducting data collection, to comply with research ethical guidelines (reference numbers 2017/65 in Pécs and 2018/229 in Budapest).

Participants were recruited through safe internal university portals, where students could register for different research studies in exchange for course credits. After registration participants were given detailed information about the aim and tasks related to the study and were asked for their consent. For 
those agreed to participate surveys were distributed through email messages which participants could fill out online.

\section{Measures}

Narcissistic Personality Inventory (NPI; Raskin \& Terry 1988) The original NPI forced participants to choose from 40 pairs of statements, one being the non-narcissistic and the other being the narcissistic option. This response format, however, only offered the elimination of socially desirable responses if very similar statements were compared, which is not the case in the NPI (Wetzel et al. 2016). On the other hand, in another study response format was shown to effect the factor structure of the NPI, where a three factor solution was more adequate for the forced-choice format, while a five factor solution offered better fit for the single-stimulus response formats (Ackerman et al. 2016). In this study, we used singlestimulus dichotomous items as the response format of NPI.

The translation was carried out in accordance with the standard test-adaptation procedure. The items were translated into Hungarian by three members of the research group. This process was followed by cross-checking, to explore the source of any possible differences and to find the most suitable alternatives. We also applied back-translation by a linguist with advanced linguistic and psychological knowledge; this helped us to improve linguistic validity and avoid translational biases. The differences between the original and back-translated texts were reviewed and revised during the final refining of the items.

Explicit Self-Esteem Explicit self-esteem was assessed using the Rosenberg Self-esteem Scale (RSES; Rosenberg 1965), a widely used 10-item instrument capturing global self-esteem. Participants respond to questions (e.g., 'I am able to do things as well as most other people') on a 4-point Likert scale ranging from 0 - 'strongly disagree' to 3 - 'strongly agree'. The measure consists of five reversed items. In the present study we have used the Hungarian translation of the measure (Urbán et al. 2014). This scale was administered only to Sample 1. The internal consistency of the scale was adequate $(\alpha=.90)$.

Eudaimonic Well-Being To measure psychological well-being, we used the Ryff and Keyes well-being scale (1995). It measures Ryff's original six factors of eudaimonic well-being (1989), with three questions for each factor: autonomy, selfacceptance, positive relations, environmental mastery, purpose in life and personal growth. The Hungarian version of the test has adequate psychometric properties (Oláh 2012), and also offers good internal consistency in our sample $(\alpha=.86)$. This scale was administered only to Sample 1 .
Vulnerable Narcissism Vulnerable narcissism was assessed using the Maladaptive Covert Narcissism Scale (Hendin and Cheek, 2013) which is the updated version of the Hypersensitive Narcissism Scale (HSNS, Hendin and Cheek 1997), developed previously. The measure consists of 23 questions, and internal consistency of the questionnaire was adequate in this study $(\alpha=.86)$. Preliminary results show that the Hungarian translation of the scale has adequate psychometric properties (Bandi 2014). This scale was administered only to Sample 2.

\section{Statistical Analysis Plan}

We applied confirmatory factor analysis with Mplus 8.0 (Muthén and Muthén 1998-2015) to estimate the degree of fit of previously proposed measurement models to the data. We tested four different measurement models that included one-factor, two-factor (Corry et al. 2008), three-factor (Ackerman et al. 2011) and seven-factor (Raskin and Terry 1988) models (for the models see the Electronic Supplementary Materials and Fig. 1). We also checked meaningful error covariances in each model. Due to the strong correlations between the first-order factors, we also tested the second-order factor models in which the secondary factor is specified to account for the covariation among multiple factors. We estimated the secondary factor model with three and seven first-order factors. In these cases second-order represents the narcissism trait. Furthermore, we also tested the bifactor models. A bifactor model represents a general narcissism dimension on which each item loaded; and specific factors on which only the specific items were loaded; and the correlations between specific factors were fixed to zero. The specification of a bifactor model requires that the specific factors correlate neither with each other nor with the general factor (Reise et al. 2010).

The advantage of bifactor modelling is the opportunity to quantify the degree of unidimensionality. Therefore, we applied the percentage of common variance attributable to the general factor through the use of the explained common variance (ECV; Bentler 2009; Ten Berge and Sočan 2004). We also used omega and omega hierarchical indices to measure how precisely a specific factor score assesses the combination of general and specific constructs and a certain target construct (Brunner et al. 2012).

Because of the binary responses to items, we used the weighted least squares mean and variance adjusted estimation method (WLSMV; Brown, 2006; Finney and DiStefano 2006). In confirmatory factor analysis, a satisfactory degree of fit requires the comparative fit index (CFI) and the TuckerLewis Index (TLI) to be higher than or close to 0.95 , and the model should be rejected when these indices are less than 0.90 (Brown, 2006). The next fit index was the root mean square error of approximation (RMSEA). RMSEA below 0.05 
indicates excellent fit, a value around 0.08 indicates adequate fit, and a value above 0.10 indicates poor fit. Closeness of model fit using RMSEA (CFit of RMSEA) is a statistical test (Brown, 2006), which evaluates the statistical deviation of RMSEA from the 0.05-value. Non-significant probability values $(p>0.05)$ indicate acceptable model fit (Brown, 2006).

Furthermore, to test the concurrent validity of the best fitting models, we used CFA with covariates in two separate university student samples from two large universities in Hungary. The covariates in the first sample were gender, explicit self-esteem and psychological well-being and, in the second sample, gender and vulnerable narcissism.

\section{Results}

\section{Testing Alternative Measurement Models of the NPI}

We tested nine measurement models on the combined sample of the three subsamples, Sample 1, Sample 2 and Sample 3 $(N=791)$. The fit indices are reported in Table 1 . According to current traditions, only Model 2, 3, 5, 7 and 8 provided acceptable fit indices. The bifactor model with three specific factors (Model 8) fitted best to the data $\left(\chi^{2}=617.0, \mathrm{CFI}=\right.$ $0.971, \mathrm{TLI}=0.965, \mathrm{RMSEA}=0.044, \mathrm{CI}[0.039-0.048]) \mathrm{com}-$ pared to the competing solutions; however, the bifactor model with two specific factors (Model 7) produced nearly as good fit indices. Therefore, factor loadings are presented for both Model 8 (Table 2) and Model 7 (Appendix, Table 4). In both bifactor models with two and three specific factors (Model 7 and Model 8) all items loaded significantly on the general narcissism factor, and the factor loadings ranged from 0.20 to 0.66 , and 0.28 to 0.67 , respectively. Four items (Items 8,11 , 32 and 3) in Model 7 and two items in Model 8 did not load significantly on the specific factors Model 7, both rather representing a global narcissism factor.

In Model 8 only three items produced lower factor loadings than the recommendations of Tabachnick and Fidell (2014), where .32 can be considered as a cut-off value for poor factor loadings. These three items were item 19, 26 and 14 with factor loadings ranging from .27 to .31 on the General factor similarly in every study conducted. These items however, had higher loadings for the specific factors Grandiose Exhibitionism and Entitlement/Exploitativeness ranging from 0.37 to 0.58 across the three studies.

We estimated common variance index in the models and found that the global narcissism factor explains $58.9 \%$ of the common variance in the bifactor model with two specific factors (Model 7) and 53.5\% in the three specific factors solution (Model 8); therefore, a meaningful global factor seems to be present. The explained variances of the specific factors are also reported in Table 2 and Appendix, Table 4.

We evaluated the internal consistency of the factors by calculating Cronbach's alpha, omega and omega hierarchical coefficients. Omega coefficients assess how certain scale scores' variance is the combination of general and specific factors, therefore estimating the reliability of a latent factor (Brunner et al. 2012). The omega hierarchical coefficient, on the other hand, estimates the reliability of a latent factor, with all other latent construct variances removed (Brunner et al. 2012; Reise et al. 2010). Reise et al. (2013) proposed a strict rule that the omega hierarchical coefficients should be higher than 0.5 for the specific factors. However, our results (ranging from $0,23-0,41$ ) suggest that the specific factors explain at least $23 \%$ of the variance in specific factor scores, underlying again the importance of a general narcissism factor.

Omega coefficients are presented in Table 2 and Appendix Table 4 showing that the specific scale scores adequately represent the mixture of general narcissism and the respective specific factors.

\section{Confirmatory Factor Analysis with Covariates}

To assess the concurrent validity of the best fitting threefactor model we used confirmatory factor analysis with covariates. The standardised coefficients are presented in Table 3.

Explicit self-esteem had a significant medium-sized positive relationship with the general narcissism factor and Grandiose Exhibitionism had a negative relationship with the Entitlement/Exploitativeness specific factor. Gender, on the other hand, only had a significant positive relationship with Entitlement/Exploitativeness. In the second sample, vulnerable narcissism had a positive relationship with the general factor and Entitlement/Exploitativeness, while it had a negative relationship with the leadership factor. Gender had a significant negative relationship with the general narcissism factor and the Leadership/Authority specific factor.

\section{Study 2}

\section{Method}

\section{Participants}

Participants in Study 2 were 319 university students (73\% women, mean age $=20.18 ; \mathrm{SD}=2.31$ ) from a first-year international student pool at a large Dutch university. Participants were recruited through safe internal university portals, where students could register for different research studies in exchange for course credits. After registration participants were given detailed information about the aim and tasks related to the study and were asked for their consent. For those agreed to participate surveys were distributed through email messages which participants could fill out online. The study was 
Table 1 Competing measurement models of grandiose narcissism: confirmatory factor analysis

\begin{tabular}{|c|c|c|c|c|c|c|c|c|}
\hline No & Models & $\begin{array}{l}\text { No of } \\
\text { items }\end{array}$ & $x^{2}$ & df & CFI & TLI & RMSEA $[90 \% \mathrm{CI}]$ & $\begin{array}{l}\text { Pclose of } \\
\text { RMSEA }\end{array}$ \\
\hline \multicolumn{9}{|c|}{ Study 1} \\
\hline \multicolumn{9}{|c|}{ First-order models } \\
\hline 1 & One-factor model with error covariances ${ }^{\#}$ & 40 & 2685.1 & 735 & 0.865 & 0.856 & $0.058[0.056-0.060]$ & $<0.001$ \\
\hline 2 & Two-factor model (Corry et al. 2008) & 23 & 1298.0 & 229 & 0.912 & 0.903 & $0.077[0.073-0.081]$ & 0.001 \\
\hline $2 \mathrm{a}$ & Two-factor model (Corry et al. 2008) with error covariances ${ }^{\#}$ & 23 & 822.8 & 226 & 0.951 & 0.945 & $0.058[0.054-0.062]$ & 0.001 \\
\hline 3 & Three-factor model (Ackerman et al. 2011) & 25 & 1705.0 & 272 & 0.889 & 0.877 & $0.082[0.078-0.085]$ & $<0.001$ \\
\hline $3 \mathrm{a}$ & Three-factor model (Ackerman et al. 2011) with error covariances ${ }^{\# \#}$ & 25 & 1011.7 & 268 & 0.942 & 0.935 & $0.059[0.055-0.063]$ & $<0.001$ \\
\hline 4 & Seven-factor model (Raskin and Terry 1988) & 40 & 2400.0 & 719 & 0.883 & 0.873 & $0.054[0.052-0.057]$ & 0.002 \\
\hline $4 \mathrm{a}$ & Seven-factor model (Raskin and Terry 1988) with error covariances & 40 & 2134.1 & 715 & 0.901 & 0.892 & $0.050[0.048-0.053]$ & 0.479 \\
\hline \multicolumn{9}{|c|}{ Second-order models (one second-ordered factor with first-order factors) } \\
\hline 5 & Three first-order factors based on Model $3 \mathrm{a}^{\# \# \#}$ & 25 & 947.3 & 267 & 0.947 & 0.941 & $0.057[0.053-0.061]$ & 0.002 \\
\hline 6 & Seven first-order factors based on Model $4 \mathrm{a}^{\# \# \#}$ & 40 & 2140.8 & 730 & 0.902 & 0.895 & $0.049[0.047-0.052]$ & 0.655 \\
\hline \multicolumn{9}{|c|}{ Bifactor models (one general and specific factors) } \\
\hline 7 & Two specific factors based on Model $2 \mathrm{a}^{\# \#}$ & 23 & 579.9 & 204 & 0.969 & 0.962 & $0.048[0.044-0.053]$ & 0.729 \\
\hline 8 & Three specific factors based on Model $3 \mathrm{a}^{\# \# \#}$ & 25 & 617.0 & 246 & 0.971 & 0.965 & $0.044[0.039-0.048]$ & 0.993 \\
\hline 9 & Seven specific factor based on Model $4^{\# \# \#}$ & 40 & 1927.8 & 698 & 0.915 & 0.904 & $0.047[0.045-0.050]$ & 0.968 \\
\hline \multicolumn{9}{|c|}{ Study 2} \\
\hline 1 & Bifactor model with two specific factors & 23 & 524.4 & 204 & 0.955 & 0.944 & $0.070[0.063-0.078]$ & $<0.001$ \\
\hline 2 & Bifactor model with three specific factors & 25 & 588.4 & 246 & 0.954 & 0.944 & $0.066[0.059-0.073]$ & $<0.001$ \\
\hline \multicolumn{9}{|c|}{ Study 3} \\
\hline 1 & Bifactor model with two specific factors $\# \#$ & 23 & 507.17 & 204 & 0.928 & 0.911 & $0.079[0.071-0.088]$ & $<0.001$ \\
\hline 2 & Bifactor model with three specific factors & 25 & 529.34 & 246 & 0.939 & 0.925 & $0.070[0.062-0.078]$ & $<0.001$ \\
\hline
\end{tabular}

Note: Study 1: $N=792$. Study 2: $N=319$. Study 3: $\mathrm{N}=237^{\#}$ : Error covariances are allowed between Item 7 (I like to be the centre of attention) and Item 30 (I really like to be the centre of attention); Item 19 (I like to look at my body) and Item 29 (I like to look at myself in the mirror); Item 19 (I like to look at my body) and Item 15 (I like to display my body). ${ }^{\# \#}$ : Error covariances are allowed between Item 7 and Item 30; Item 19 and Item 29 ; Item 19 and Item 15; Item 1 (I have a natural talent for influencing people) and Item 13 (I find it easy to manipulate people). ${ }^{\text {\#\# }}$ : Error covariances are allowed between Item 7 (I like to be the centre of attention) and Item 30 (I really like to be the centre of attention); Item 1 (I have a natural talent for influencing people) and Item 13 (I find it easy to manipulate people)

approved by the university research ethical committee (registration number: $18102-\mathrm{S})$.

\section{Measures}

Narcissistic Personality Inventory (NPI; Raskin \& Terry 1988) In Study 2 the rating-scale version of the Narcissistic Personality Inventory (NPI-40) was used, which presents the original 40 narcissistic options of the NPI. Participants need to decide to which degree from a scale from 1 to 5 are those statements are describing them. This response format is recently gaining popularity (Wetzel et al. 2016; Miller 2018), and it offers the opportunity to evaluate the bifactor model with a different response format as well. In Study 2 we used the original English version of the NPI.

Narcissistic Grandiosity Scale (NGS; Rosenthal et al. 2007) The NGS is an adjective scale that contains 16 items. Participants are presented with the 16 adjectives (eg. Glorious,
Prestigious), and they need to rate how much these adjectives describe themselves. The scale has good psychometric properties (Crowe et al., 2016), and it is in strong association with other measures of narcissistic grandiosity. The internal consistency of the scale was adequate $(\alpha=.94)$.

Pathological Narcissism Inventory (PNI; Pincus et al. 2009) The PNI assesses seven factors of both vulnerable and grandiose narcissism. Wright et al. (2010) proposed a factor structure of two higher order dimensions: factors Exploitativeness, Self-Sacrificing Self-Enhancement and Grandiose Fantasies form the grandiosity factor while Contingent Self-Esteem, Hiding the Self, Devaluing and Entitlement rage factors form the vulnerability factor. Items are rated from "Not at all like me" as 0 to "Very much like me" as 5 . The internal consistency of the scale was adequate $(\alpha=.94)$.

Narcissistic Vulnerability Scale (NVS; Crowe Et al., 2018) The NVS is also an adjective based measure similarly to the NGS, 


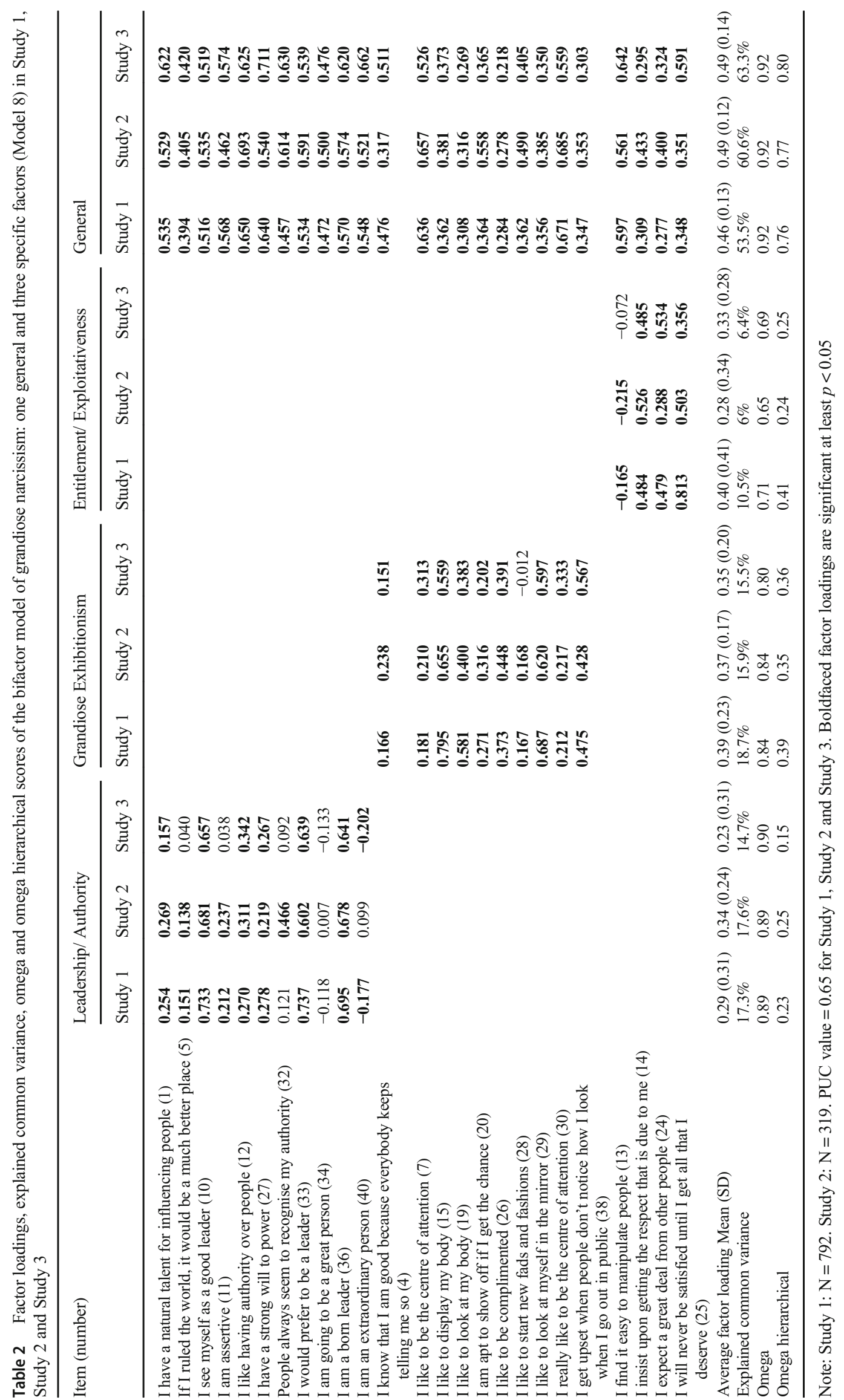


Table 3 Correlates of the bifactor model of grandiose narcissism: confirmatory factor analyses with covariates (Study 1, Study 2 and Study 3 )

\begin{tabular}{|c|c|c|c|c|}
\hline & General factor & Leadership/ Authority & $\begin{array}{l}\text { Grandiose } \\
\text { exhibitionism }\end{array}$ & $\begin{array}{l}\text { Entitlement/ } \\
\text { Exploitativeness }\end{array}$ \\
\hline \multicolumn{5}{|l|}{ Study $1(N=629)$} \\
\hline \multicolumn{5}{|l|}{ Sample $1(N=215)$} \\
\hline Gender & -0.07 & -0.13 & 0.01 & 0.23 \\
\hline Eudaimonic well-being & 0.13 & 0.04 & -0.17 & 0.05 \\
\hline Explicit self-esteem & 0.27 & -0.12 & 0.25 & -0.36 \\
\hline $\mathrm{R}^{2}$ & $15 \%$ & $2 \%$ & $3 \%$ & $19 \%$ \\
\hline \multicolumn{5}{|l|}{ Sample $2(\mathrm{~N}=414)$} \\
\hline Gender & 0.20 & -0.18 & 0.13 & 0.43 \\
\hline Vulnerable narcissism & -0.18 & -0.19 & 0.03 & 0.11 \\
\hline $\mathrm{R}^{2}$ & $7 \%$ & $8 \%$ & $2 \%$ & $21 \%$ \\
\hline \multicolumn{5}{|l|}{ Study $2(\mathrm{~N}=319)$} \\
\hline Gender & -0.20 & -0.01 & 0.23 & 0.23 \\
\hline $\mathrm{PNI}^{*}$ & 0.32 & -0.02 & 0.24 & 0.59 \\
\hline PNI Vulnerability factors ${ }^{*}$ & 0.09 & -0.07 & 0.13 & 0.53 \\
\hline PNI Grandiosity factors ${ }^{*}$ & 0.55 & -0.08 & 0.36 & 0.57 \\
\hline $\mathrm{MCNS}^{*}$ & 0.15 & -0.02 & 0.19 & 0.51 \\
\hline $\mathrm{NVS}^{*}$ & 0.03 & -0.07 & 0.05 & 0.36 \\
\hline NGS* & 0.54 & 0.30 & 0.43 & 0.16 \\
\hline \multicolumn{5}{|c|}{ Explicit self-esteem with gender controlled } \\
\hline Gender & -0.16 & -0.05 & 0.17 & 0.24 \\
\hline Explicit self-esteem & 0.11 & 0.27 & 0.39 & -0.10 \\
\hline $\mathrm{R}^{2}$ & $4 \%$ & $8 \%$ & $17 \%$ & $7 \%$ \\
\hline \multicolumn{5}{|l|}{ Study 3 (N = 237) } \\
\hline Extraversion & 0.36 & 0.37 & 0.21 & 0.06 \\
\hline Agreeableness & -0.24 & -0.10 & -0.04 & 0.01 \\
\hline Conscientiousness & -0.06 & 0.20 & -0.08 & 0.16 \\
\hline Negative emotionality & -0.24 & -0.01 & 0.11 & 0.38 \\
\hline Open-mindedness & 0.18 & 0.02 & 0.08 & -0.02 \\
\hline
\end{tabular}

Note: Boldfaced regression coefficients are significant at least $p<.05$. Each covariate is regressed separately in order to avoid the multicollinearity of covariates. PNI: Pathological Narcissism Inventory; MCNS: Maladaptive Covert Narcissism Scale; NVS: Narcissistic Vulnerability Scale; NGS: Narcissistic Grandiosity Scale with 11 items such as Underappreciated, Insecure or Fragile. Participants needed to decide on a scale from 1 to 7 how much these adjectives describe them. The internal consistency of the scale was adequate $(\alpha=.87)$.

\section{Maladaptive Covert Narcissism Scale (MCNS; Hendin \& Cheek,} 2013) The MCNS is the updated version of the Hypersensitive Narcissism Scale (HSNS; Hendin \& Cheek 1997) developed previously to assess vulnerable narcissism. The measure consists of 23 items. The internal consistency of the scale was adequate $(\alpha=.85)$.

Rosenberg Self-Esteem Scale (RSES; Rosenberg 1965) Explicit self-esteem was assessed using the Rosenberg Self-esteem Scale (RSES; Rosenberg 1965), a widely used 10-item scale capturing global self-esteem. Participants respond to questions (e.g., "I am able to do things as well as most other people") on a 4-point Likert scale ranging from 0 - "strongly disagree" to 3 - "strongly agree". The measure consists of five reversed items. The internal consistency of the scale was adequate $(\alpha=.88)$.

\section{Results}

In Study 2 we tested the fit of the two bifactor models on a different sample with confirmatory factor analysis using the weighted least squares mean and variance adjusted estimation method (WLSMV; Brown, 2006; Finney and DiStefano 2006) similarly to Study 1, using Mplus version 8.0. We used the full information maximum likelihood estimator to deal with missing data (Muthén and Muthén, 1998-2015). The fit indices are reported in Table 1 . The models showed 
acceptable fit to the data according to current traditions, although the fit was slightly more modest than in Study 1. Standardized factor loadings of the general factor ranged from 0.28 to 0.69 on both the two and three factor models (Table 2).

We estimated common variance index in the models and found that the global narcissism factor explains $63.6 \%$ of the common variance in the two-factor model and $60.6 \%$ in the three-factor model (see Table 2 and Appendix Table 4 for more details). These results suggest, that the relevance of the global factor was also supported in Study 2.

\section{Associations of the General and the Specific Factors}

To assess the associations of the best fitting three-factor model we used confirmatory factor analysis with covariates, where we regressed the factors on the covariates. The standardised coefficients are presented in Table 3. Each covariate was regressed separately.

The general factor of grandiose narcissism was in positive medium sized association with other commonly used measures of grandiose narcissism for example the grandiosity factors of the PNI, or the NGS. Furthermore, most measures of vulnerable narcissism were unrelated with the general factor. Leadership/Authority specific factor was associated significantly only with the NGS. Grandiose Exhibitionism moderately associated with other grandiose narcissism measures, and weaker but not negligible associations with vulnerability measures. Entitlement/Exploitativeness on the other hand showed medium-strong associations with both measures of narcissistic vulnerability and grandiosity. We also observed modest gender differences on the general narcissism factor favouring men, and on both the Grandiose Exhibitionism and Entitlement/Exploitativeness factor favouring women.

Explicit self-esteem had significant positive relationship only with Grandiose Exhibitionism and Leadership/ Authority factors while having a non-significant negative relationship with the Entitlement/Exploitativeness specific factor.

\section{Study 3}

\section{Method}

\section{Participants and Procedure}

Participants in Study 3 were 237 university students (75\% women, mean age $=22.10 ; \mathrm{SD}=3.91$ ) from a student pool at a large Hungarian university. Participants were recruited through safe internal university portals, where students could register for different research studies in exchange for course credits. After registration participants were given detailed information about the aim and tasks related to the study and were asked for their consent. For those agreed to participate surveys were distributed through email messages which participants could fill out online. The study was approved by the university research ethical committee (registration number: 2018/229).

\section{Measures}

Narcissistic Personality Inventory (NPI; Raskin \& Terry, 1988) In Study 3 also the Likert version of the Narcissistic Personality Inventory (NPI-40) was used (Wetzel et al., 2016; Miller, 2018), administered in Hungarian. Item response distributions were skewed, therefore we handled the scale as ordinal in our analysis.

Big Five Inventory (BFI-2; Soto \& John, 2017) The big five personality traits were measured with the Big Five Inventory (BFI-2), which contains 60 items forming the factors Extraversion, Agreeableness, Conscientiousness, Negative emotionality and Open-mindedness. Participants need to decide to which degree from a scale of 1 to 5 are the statements describing them. The Hungarian version of the test was translated based on the protocol of Beaton et al. (2000). The internal consistency was mostly acceptable of the trait measures, except for the open-mindedness trait, which offered limited reliability: extraversion $(\alpha=.82)$, agreeableness $(\alpha=.79)$, conscientiousness $(\alpha=.72)$, negative emotionality $(\alpha=.86)$, open-mindedness $(\alpha=.49)$.

\section{Results}

In Study 3 we tested the fit of the two bifactor models with a confirmatory factor analysis using the weighted least squares mean and variance adjusted estimation method (WLSMV; Brown, 2006; Finney and DiStefano, 2006) similarly to Study 1 and Study 2, using Mplus version 8.0. We used the full information maximum likelihood estimator to deal with missing data (Muthén and Muthén, 1998-2015). The fit indices are reported in Table 1. The models showed acceptable fit to the data according to current traditions, the fit indices were similar than in Study 2. Standardized factor loadings of the general factor ranged from 0.22 to 0.71 on both the two and three factor models (Table 2 and Appendix, Table 4).

\section{Measurement Invariance}

In Study 3 we used the Likert version of the NPI similarly to Study 2, however we administered the test in Hungarian. Item response distributions were skewed, therefore we handled the scale as ordinal in our analysis following the recommendation of Finney and DiStefano (2006). They argued, that although it is a common practice in psychological research to handle rating scales as linear, in case of non-normally distributed data 
maximum likelihood-based $\chi^{2}$ values can be inflated, and model fit indices can also be underestimated (Finney \& DiStefano, 2006).To overcome the possible differences with the translation we tested the invariance of the measurement with the adapted version of the NPI. Metric invariance could not be calculated due to the bifactor model and the categorical items, although scalar invariance also contains metric invariance. The configural and scalar model were significantly different from each other $\left(\chi^{2}=389.41, \mathrm{df}=117 ; p<0.001\right)$, however the differences in the fit indices (configural model: $\chi^{2}=1112.55, \mathrm{CFI}=0.948, \mathrm{TLI}=0.937, \mathrm{RMSEA}=0.067, \mathrm{CI}$ [0.062-0.073]; scalar model: $\chi^{2}=1434.50, \mathrm{CFI}=0.931$, $\mathrm{TLI}=0.932, \mathrm{RMSEA}=0.070$, CI $[0.065-0.075])$ diminished less than the recommended cut-off values proposed by Chen (2007). The allowed difference in CFI and TLI measures across the configural and scalar model could not be higher than 0.02 (Chen, 2007), which was 0.017 in the case of CFI change and 0.005 in TLI change in our model.

\section{Associations of the General and the Specific Factors}

In Study 3 the associations of the bifactor model of the NPI was also tested with a Big Five personality inventory (Table 3). Extraversion was positively associated with the general, the Leadership/Authority and the Grandiose exhibitionism factors. Agreeableness was negatively related with the general factor and it was unrelated to the specific factors. Conscientiousness was in a significant positive association with only the Leadership/Authority factor, while openmindedness was only positively associated with the general factor. Negative emotionality on the other hand was negatively related to the general factor, while positively to the Entitlement/Exploitativeness factor.

\section{Discussion}

Our study supported the bifactor measurement models of grandiose narcissism. Besides the strong general narcissism factor, the specific factors also have meaningful, but much less, explanatory power. Previous research found mixed results regarding the factor structure of the Narcissistic Personality Inventory (NPI), applying either principal components analysis (Emmons, 1987; Raskin \& Terry, 1988) or exploratory factor analysis (Ackerman et al., 2011, 2015; Corry et al. 2008; Kubarych et al., 2004) or confirmatory factor analysis (Ackerman et al., 2011; Kubarych et al., 2004).

Applying bifactor modelling in clinical measurement is gaining more popularity as it can differentiate between the shared variance of an underlying general factor and a subset of items which share variance in addition to this general factor (Rodriguez, Reise, \& Haviland, 2016).
In bifactor models every item is determined by two separate latent factors, therefor two factor loadings exist: the loading on the general factor, and the loading on one of the specific factors. In our three studies the Explained Common Variance was ranging from $53.5 \%-63.3 \%$ and the Omega hierarchical was ranging from .76 to .80 for the General narcissism factor. Therefore, we can conclude, that this General factor plays the most important role in interpreting the results, while the specific factors have a substantially lower explanatory power, although a few items seem to reflect these specific factors to a greater extent. Moreover, the good fit of the model and the strong associations of the general factor with other measures of grandiose narcissism support the validity of the bifactor model.

Both the competing two- and three-factor solutions yielded an adequate fit to the data, however the three-factor solution provided a slightly closer fit, and it uses more items from the original construct.

As Ackerman and his colleagues argued (2016) based on a series of exploratory factor analyses, differences can occur between the factor structure of the single stimulus and forces choice response formats. In their study a five-factor solution was well-suited to the single stimulus format of the NPI. Three items formed a separate Vanity factor, although these items also had moderate cross-loadings with their Exhibitionism factor (.44-.50). In our solution the bifactor model offered the chance of disentangling the variance coming from the general narcissism factor and the specific factor of Grandiose Exhibitionism, which was originally proposed for the forced-choice response format of the NPI (Ackerman et al., 2011). The significant factor loadings of the items in both the general, both the specific factors and the good fit of the measurement model suggest, that the original factor solution of Ackerman et al. (2011) could be used in the NPI with a single-stimulus format as well when a bifactorial model is applied.

Therefore, our study also implies that it can be advisable to use the NPI in a bifactor measurement setting as latent variables in further research.

In these studies, we used two separate single-stimulus response formats of the NPI, namely the binary and the rating scale option in two different languages. Regardless of the differences in response formats used, the bifactor model with one general factor and three specific factors offered good fit to the data. Neither the Omega hierarchical measures nor the factor loadings were substantially different between the binary and the rating scale options (for the details see Table 2). Based on these results, we can conclude, that the underlying constructs measured in the NPI seem to be similar when applying the bifactor model, especially when we are using ordinal scaling following the recommendation of Finney and DiStefano (2006).

We also tested measurement invariance between the Hungarian and English versions of the NPI in a rating scale 
setting. Our results supported the assumption that the measurement model was invariant across the translations which further improves the generalizability of the bifactor model, showing similar factor structure in two different cultural settings.

Despite the acceptable fit provided by bifactor models in general results should be interpreted with caution (Bonifay, Lane \& Reise, 2017; Rodriguez et al., 2016). The two main concerns raised are that first, bifactor models tend to fit better to any possible data therefore can result in overfitting the studied model (Bonifay \& Cai; 2017). Second, it might be hard to interpret what remains of a specific factor, after accounting for an orthogonal general factor (for details see Rodriguez et al., 2016). These are indeed serious concerns, however our aim with the present study was not only to report a well-fitting model, but to investigate to what degree does the NPI seem a multidimensional construct by nature. Our results suggest, that with relevant criterion variables and other concurrent measures of narcissism our bifactor model showed mostly well-interpretable findings.

The results of the bifactor measurement model of the NPI were mainly in line with previous research. Both the other two measures of narcissistic grandiosity shown a strong positive association with the general factor, and weaker but still significant association with Grandiose Exhibitionism and Entitlement/Exploitativeness. Vulnerable narcissism on the other hand was mainly unrelated with both the general factor both the specific factors except for the Entitlement/ Exploitativeness factor. This positive medium sized association is in line with other studies (Crowe et al., 2018a and b; Krusemark et al., 2018), sometimes Entitlement/ Exploitativeness has been treated as an index of vulnerable narcissism (Rhodewalt \& Peterson, 2009) despite the several differences between the two constructs including their different associations with self-esteem, or that people scoring higher on Entitlement/Exploitativeness are less concerned about social evaluation and avoiding aversive states (Hart et al., 2017). Furthermore, vulnerable narcissism involves being selfinhibited and constantly feeling uncertain, with a great reliance on others' approval (Kealy \& Rasmussen, 2012; Morf \& Rhodewalt, 2001), all of which are in contrast with the content of the other specific factors.

The validity of a bifactor model was also tested with covariates. General and specific factors have shown different relationships with explicit self-esteem: whereas the general factor and the Grandiose Exhibitionism specific factor were positively related to explicit self-esteem, the Entitlement/ Exploitativeness factor was negatively related to it both in Study 1 and Study 2, in different strength. This might have several explanations. Grandiose narcissism is consistently found to be in positive relationship with explicit self-esteem (Hyatt et al., 2018; Di Pierro et al., 2016; Maxwell et al., 2011); however, our results show that this, on the one hand is based on the general factor and, on the other, on Grandiose Exhibitionism. Individuals with defensive high self-esteem can be afraid to admit negative self-feelings, therefore presenting an overly positive or grandiose image might affect answering self-esteem related items (Kernis, 2003). In this sense, reported high self-esteem can also be part of grandiosity itself. Entitlement/Exploitativeness, on the other hand, is in negative relationship with self-esteem. This also is consistent with previous results assessing the Entitlement/Exploitativeness subscale (Ackerman and Donnellan, 2013) alone, explaining this type of entitlement as being driven by vulnerability.

Big Five personality traits were also assessed in Study 3, and the results were mostly consistent with previous studies (Ackerman et al., 2011; Dinić \& Vujić, 2018), however the general factor plays a significant role in all big five traits except conscientiousness. Agreeableness was rather negatively associated with the general factor, and it was unrelated to the Entitlement/Exploitativeness specific factor, which is different from previous studies (eg. Ackerman et al., 2011; Dinić $\&$ Vujić, 2018). Negative emotionality on the other hand was negatively related to the general factor and positively to Entitlement/Exploitativeness which might also confirm, that this specific factor can be considered the maladaptive aspect of grandiose narcissism. It also means, that the general narcissism factor is masking the association between Entitlement/ Exploitativeness and negative emotionality. Similarly, specific factor's association with Agreeableness and Openmindedness is negligible if the general factor is already accounted for. These results also support the advantages of the bifactor model, as it can differentiate the effect of the general and specific factors in the associations with other covariates.

Although in both studies gender was a significant covariate, there were some differences between the studies. Women tended to score higher on the Entitlement/Exploitativeness specific factor in both studies, while men scored higher on the general factor. Grandiose Exhibitionism was also higher in female participants in 2 out of the 3 samples. Our findings are in contrast with a recent meta-analysis (Grijalva et al., 2015), which found that men scored higher on every specific narcissistic factor than women. This discrepancy may highlight the possibility that culture moderates gender differences in narcissism; however, our results in both studies were captured from samples of university students, and therefore do not represent the general population of neither Hungary, nor the Netherlands. Students applying to psychological studies in both countries may face significant competition, which might be in connection with higher levels of narcissism.

A further possible explanation is that recent generations are more narcissistic than previous ones, in particular, women have become more similar to men with the changing social roles (Grijalva et al., 2015). This, however, only provides a partial explanation as, in most studies - despite the changes - 
men are found to be more exploitative and to feel more entitled. The exact items that show the biggest gender difference favouring women were: 'I expect a great deal from other people' and 'I insist upon getting the respect that is due to me'. This finding is consistent with the observation of a strong gender inequality (WEF 2017), implying higher awareness among women about receiving the same respect as is afforded men. Furthermore, these differences are larger in the sample of psychology students, whose curricula and social psychological studies often contain gender inequality. Therefore, it is likely that this difference is not closely connected to feeling entitled. The other item related to the specific factor, 'I find it easy to manipulate people', was found to be endorsed more often by male, as opposed to female, participants. This finding is consistent with previous results (Grijalva et al., 2015).

\section{Conclusions}

According to our findings, grandiose narcissism as a general factor accounts for at least half of the variance captured in the NPI while the role of specific factors remains limited. Therefore, the measurement of this general narcissism factor seems important when we would like to understand the associations with other psychological constructs. Based on our results the general narcissism factor and the relevant specific factors offered by Ackerman and his colleagues (2011) can be assessed using a shorter version of the NPI containing 25 items. Associations of these factors with other relevant variables seem to justify the validity of the bifactor model, although further research is needed to identify the associations with other relevant constructs, in other languages or other cultural settings. Moreover, further studies are needed to identify the role of the specific factors, namely what remains of these factors after the variance accounted for by the general grandiose narcissism factor is substracted from them, and how these specific factors are related to other relevant psychological constructs.

Our study also aims to offer results regarding the response format used in the NPI. According to our findings, the factor structure offered for the forced-choice response format of the NPI (Ackerman et al., 2011) offers acceptable fit to the data if the single-stimulus response is used with the bifactor measurement model.

\section{Limitations}

The present study also has its limitations. First, we used university samples in both studies, which does not represent the general population of the two countries, however most of the current literature of narcissism is based on student samples. Second, a wider range of covariates might be included into the analyses in the future supplemented with observation-based or expert rating variables. Third, in all of our studies, we used the single-stimulus response format versions of the NPI. Further studies are needed to validate, if this bifactorial model could also be applied in the original, forced choice response format.

Funding Information Open access funding provided by Eötvös Loránd University.

\section{Compliance with Ethical Standards}

Conflict of Interest The authors declare that they have no conflict of interest.

Ethical Approval Approval was obtained from the ethics committee of Eotvos Lorand University (Ethics approval number: 2018/229) and the University of Pécs (Ethics approval number: 2017/65). The procedures used in this study adhere to the tenets of the Declaration of Helsinki.

Informed Consent Informed consent was gathered before the studies from all of the participants.

\section{Appendix}

Table 4 Factor loadings, explained common variance, omega and omega hierarchical scores of the bifactor model of grandiose narcissism: one general and two specific factors (Model 7) in Study 1 and Study 2

\begin{tabular}{|c|c|c|c|c|c|c|c|c|c|}
\hline \multirow[t]{2}{*}{ Item (number) } & \multicolumn{3}{|c|}{ Leadership / Authority } & \multicolumn{3}{|c|}{ Exhibitionism / Entitlement } & \multicolumn{3}{|c|}{ General } \\
\hline & Study 1 & Study 2 & Study 3 & Study 1 & Study 2 & Study 3 & $\begin{array}{l}\text { Study } \\
1\end{array}$ & Study 2 & Study 3 \\
\hline I have a natural talent for influencing people (1) & 0.164 & 0.250 & 0.123 & & & & 0.610 & 0.541 & 0.642 \\
\hline I will be a success ( 8 ) & 0.122 & 0.070 & 0.226 & & & & 0.454 & 0.486 & 0.355 \\
\hline I see myself as a good leader (10) & 0.707 & 0.682 & 0.688 & & & & 0.555 & 0.539 & 0.510 \\
\hline I am assertive (11) & 0.099 & 0.212 & -0.061 & & & & 0.644 & 0.484 & 0.604 \\
\hline I like having authority over people (12) & 0.233 & 0.311 & 0.240 & & & & 0.655 & 0.688 & 0.670 \\
\hline I have a strong will to power (27) & 0.240 & 0.210 & 0.178 & & & & 0.636 & 0.552 & 0.732 \\
\hline
\end{tabular}


Table 4 (continued)

\begin{tabular}{|c|c|c|c|c|c|c|c|c|c|}
\hline \multirow[t]{2}{*}{ Item (number) } & \multicolumn{3}{|c|}{ Leadership / Authority } & \multicolumn{3}{|c|}{ Exhibitionism / Entitlement } & \multicolumn{3}{|c|}{ General } \\
\hline & Study 1 & Study 2 & Study 3 & Study 1 & Study 2 & Study 3 & $\begin{array}{l}\text { Study } \\
1\end{array}$ & Study 2 & Study 3 \\
\hline People always seem to recognise my authority (32) & 0.073 & 0.448 & 0.083 & & & & 0.492 & 0.624 & 0.653 \\
\hline I would prefer to be a leader (33) & 0.723 & 0.584 & 0.626 & & & & 0.558 & 0.611 & 0.553 \\
\hline I am a born leader (36) & 0.672 & 0.660 & 0.659 & & & & 0.597 & 0.591 & 0.615 \\
\hline I would do almost anything on a dare (3) & & & & -0.116 & 0.112 & -0.018 & 0.403 & 0.356 & 0.397 \\
\hline $\begin{array}{l}\text { I know that I am a good person because everybody } \\
\text { keeps telling me so (4) }\end{array}$ & & & & 0.163 & 0.296 & 0.157 & 0.484 & 0.279 & 0.508 \\
\hline I like to be the centre of attention (7) & & & & 0.197 & 0.154 & 0.270 & 0.647 & 0.668 & 0.529 \\
\hline I insist upon getting the respect that is due to me (14) & & & & 0.256 & 0.250 & 0.126 & 0.256 & 0.395 & 0.308 \\
\hline I like to display my body (15) & & & & 0.714 & 0.655 & 0.601 & 0.327 & 0.350 & 0.374 \\
\hline I like to look at my body (19) & & & & 0.375 & 0.297 & 0.470 & 0.303 & 0.312 & 0.238 \\
\hline I am apt to show off if I get the chance (20) & & & & 0.326 & 0.324 & 0.156 & 0.333 & 0.560 & 0.371 \\
\hline I expect a great deal from other people (24) & & & & 0.332 & 0.179 & 0.106 & 0.199 & 0.362 & 0.310 \\
\hline $\begin{array}{l}\text { I will never be satisfied until I get all that I deserve } \\
\text { (25) }\end{array}$ & & & & 0.361 & 0.203 & 0.131 & 0.272 & 0.348 & 0.587 \\
\hline I like to start new fads and fashions (28) & & & & 0.202 & 0.274 & -0.011 & 0.334 & 0.465 & 0.395 \\
\hline I like to look at myself in the mirror (29) & & & & 0.665 & 0.572 & 0.693 & 0.318 & 0.371 & 0.290 \\
\hline I really like to be the centre of attention (30) & & & & 0.244 & 0.194 & 0.293 & 0.659 & 0.692 & 0.566 \\
\hline $\begin{array}{l}\text { I get upset when people don't notice how I look } \\
\text { when I } \\
\text { go out in public (38) }\end{array}$ & & & & 0.583 & 0.545 & 0.512 & 0.275 & 0.307 & 0.300 \\
\hline I am more capable than other people (39) & & & & 0.124 & 0.032 & 0.042 & 0.443 & 0.581 & 0.619 \\
\hline Average factor loadings Mean (SD) & $\begin{array}{l}0.34 \\
(0.28)\end{array}$ & $\begin{array}{l}0.38 \\
(0.22)\end{array}$ & $\begin{array}{l}0.31 \\
(0.28)\end{array}$ & $\begin{array}{r}0.32 \\
(0.22)\end{array}$ & $\begin{array}{l}0.29 \\
(0.18)\end{array}$ & $\begin{array}{l}0.25 \\
(0.23)\end{array}$ & $\begin{array}{l}0.45 \\
(0.15)\end{array}$ & $\begin{array}{l}0.49 \\
(0.13)\end{array}$ & $\begin{array}{l}0.48 \\
(0.14)\end{array}$ \\
\hline Explained common variance & $18.4 \%$ & $18.6 \%$ & $16.4 \%$ & $22.7 \%$ & $17.8 \%$ & $17.7 \%$ & $58.9 \%$ & $63.6 \%$ & $65.8 \%$ \\
\hline Omega & 0.89 & 0.90 & 0.90 & 0.83 & 0.85 & 0.83 & 0.91 & 0.92 & 0.91 \\
\hline Omega hierarchical & 0.23 & 0.28 & 0.20 & 0.36 & 0.27 & 0.23 & 0.71 & 0.75 & 0.78 \\
\hline
\end{tabular}

Note: Study 1: $N=792$. Study 2: N = 319. PUC value for both Study 1 and Study 2: 0.50; for Study 3: 0.48. Boldfaced factor loadings are significant at least $\mathrm{p}<0.05$

Open Access This article is licensed under a Creative Commons Attribution 4.0 International License, which permits use, sharing, adaptation, distribution and reproduction in any medium or format, as long as you give appropriate credit to the original author(s) and the source, provide a link to the Creative Commons licence, and indicate if changes were made. The images or other third party material in this article are included in the article's Creative Commons licence, unless indicated otherwise in a credit line to the material. If material is not included in the article's Creative Commons licence and your intended use is not permitted by statutory regulation or exceeds the permitted use, you will need to obtain permission directly from the copyright holder. To view a copy of this licence, visit http://creativecommons.org/licenses/by/4.0/.

\section{References}

Ackerman, R. A., \& Donnellan, M. B. (2013). Evaluating self-report measures of narcissistic entitlement. Journal of Psychopathology and Behavioral Assessment, 35(4), 460-474. https://doi.org/10. 1007/s10862-013-9352-7.

Ackerman, R. A., Donnellan, M. B., Roberts, B. W., \& Fraley, R. C. (2016). The effect of response format on the psychometric properties of the narcissistic personality inventory: Consequences for item meaning and factor structure. Assessment, 23(2), 203-220.

Ackerman, R. A., Witt, E. A., Donnellan, M. B., Trzesniewski, K. H., Robins, R. W., \& Kashy, D. A. (2011). What does the narcissistic personality inventory really measure? Assessment, 18, 67-87. https://doi.org/10.1177/1073191110382845.

Aghababaei, N., \& Błachnio, A. (2015). Well-being and the dark triad. Personality and Individual Differences, 86, 365-368.

Bandi, B., Bolgár, D., \& Nagy, L. (2017). The psychodynamic correlations of narcissism: The relationship between the Szondi test and the orthogonal narcissism concept. Szondiana, 37(1), 102-124.

Bandi, Sz. (2014). Az NPI és a HSNS-MCNS tesztek pszichometriai eredményei, korábbi empirikus adatok. [psychometric properties of NPI and HSNS-MCNS scales] [in Hungarian] unpublished manuscript, University of Pécs, Pécs Hungary Pécsi Tudományegyetem.

Beaton, D. E., Bombardier, C., Guillemin, F., \& Ferraz, M. B. (2000). Guidelines for the process of cross-cultural adaptation of self-report measures. Spine, 25(24), 3186-3191.

Bentler, P. M. (2009). Alpha, dimension-free, and model-based internal consistency reliability. Psychometrika, 74(1), 137-143. https://doi. org/10.1007/s11336-008-9100-1.

Brunner, M., Nagy, G., \& Wilhelm, O. (2012). A tutorial on hierarchically structured constructs. Journal of Personality, 80(4), 796-846. https://doi.org/10.1111/j.1467-6494.2011.00749.x.

Bonifay, W., \& Cai, L. (2017). On the complexity of item response theory models. Multivariate Behavioral Research, 52(4), 465-484.

Bonifay, W., Lane, S. P., \& Reise, S. P. (2017). Three concerns with applying a bifactor model as a structure of psychopathology. Clinical Psychological Science, 5(1), 184-186.

Cai, H., \& Luo, Y. L. (2018). Distinguishing Between Adaptive and Maladaptive Narcissism. In Distinguishing between adaptive and 
maladaptive narcissism, Handbook of Trait Narcissism (pp. 97104). Cham: Springer.

Cain, N. M., Pincus, A. L., \& Ansell, E. B. (2008). Narcissism at the crossroads: Phenotypic description of pathological narcissism across clinical theory, social/personality psychology, and psychiatric diagnosis. Clinical Psychology Review, 28(4), 638-656.

Campbell, W. K., \& Miller, J. D. (2012). The Emotional Dynamics of Narcissism. In The handbook of narcissism and narcissistic personality disorder: Theoretical approaches, empirical findings, and treatments. Hoboken, NJ: John Wiley \& Sons. Inc.. https://doi.org/ 10.1002/9781118093108.ch29.

Campbell, W. K., Rudich, E. A., \& Sedikides, C. (2002). Narcissism, self-esteem, and the positivity of self-views: Two portraits of selflove. Personality and Social Psychology Bulletin, 28(3), 358-368. https://doi.org/10.1177/0146167202286007.

Caspi, A., Houts, R. M., Belsky, D. W., Goldman-Mellor, S. J., Harrington, H., Israel, S., Meier, M. H., Ramrakha, S., Shalev, I., Poulton, R., \& Moffitt, T. E. (2014). The p factor: One general psychopathology factor in the structure of psychiatric disorders? Clinical Psychological Science, 2(2), 119-137.

Cheek, J. M., Hendin, H. M., Wink, P. M. (2013). An expanded version of the hypersensitive narcissism scale (the maladaptive covert narcissism scale). Association for Research in Personality (conference). Charlotte, NC. https://doi.org/10.13140/RG.2.1.3216.1761.

Chen, F. F. (2007). Sensitivity of goodness of fit indexes to lack of measurement invariance. Structural Equation Modeling: A Multidisciplinary Journal, 14(3), 464-504.

Cooper, J., \& Maxwell, N. (1995). Narcissistic Wounds: Clinical Perspectives is edited by Judy Cooper and Nilda Maxwell, and published by Whurr, London (1995, 163 pp., £14.95). In Narcissistic wounds. London: Jason Aronson Inc.. https://doi.org/10.1192/ S0007125000029433.

Corry, N., Merritt, R. D., Mrug, S., \& Pamp, B. (2008). The factor structure of the narcissistic personality inventory. Journal of Personality Assessment, 90, 593-600. https://doi.org/10.1080/ 00223890802388590.

Crowe, M. L., Edershile, E. A., Wright, A. G., Campbell, W. K., Lynam, D. R., \& Miller, J. D. (2018a). Development and validation of the narcissistic vulnerability scale: An adjective rating scale. Psychological Assessment, 30(7), 978-983.

Crowe, M. L., Sleep, C. E., Carter, N. T., Campbell, W. K., \& Miller, J. D. (2018b). Self-esteem and narcissism: An item response theory analysis of curvilinearity. Personality and Individual Differences, $128,16-20$

Di Pierro, R., Mattavelli, S., \& Gallucci, M. (2016). Narcissistic traits and explicit self-esteem: The moderating role of implicit self-view. Frontiers in Psychology, 7, 1815. https://doi.org/10.3389/fpsyg. 2016.01815.

Dinić, B. M., \& Vujić, A. (2018). Five-factor model best describes narcissistic personality inventory across different item response formats. Psychological Reports, 0033294118794404.

Emmons, R. A. (1987). Narcissism: Theory and measurement. Journal of Personality and Social Psychology, 52(1), 11-17. https://doi.org/10. 1037/0022-3514.52.1.11

Finney, S. J., \& DiStefano, C. (2006). Non-normal and categorical data in structural equation modeling. Structural equation modeling: A second course, 10(6), 269-314.

Gentile, B., Miller, J. D., Hoffman, B. J., Reidy, D. E., Zeichner, A., \& Campbell, W. K. (2013). A test of two brief measures of grandiose narcissism: The narcissistic personality inventory-13 and the narcissistic personality Inventory-16. Psychological Assessment, 25(4), $1120-1136$

Giacomin, M. (2016). Investigating grandiose narcissism as a personality process. (doctoral dissertation). Retrieved from https://scholars. wlu.ca/etd/1864/
Glover, N., Miller, J. D., Lynam, D. R., Crego, C., \& Widiger, T. A. (2012). The five-factor narcissism inventory: A five-factor measure of narcissistic personality traits. Journal of Personality Assessment, 94(5), 500-512.

Gluschkoff, K., Jokela, M., \& Rosenström, T. (2019). The general psychopathology factor: Structural stability and generalizability to within-individual changes. Frontiers in Psychiatry, 10, 594.

Grijalva, E., Newman, D. A., Tay, L., Donnellan, M. B., Harms, P. D., Robins, R. W., \& Yan, T. (2015). Gender differences in narcissism: A meta-analytic review. Psychological Bulletin, 141(2), 261-310. https://doi.org/10.1037/a0038231.

Hart, W., Adams, J., Burton, K. A., \& Tortoriello, G. K. (2017) Narcissism and self-presentation: Profiling grandiose and vulnerable Narcissists' self-presentation tactic use. Personality and Individual Differences, 104, 48-57.

Hendin, H. M., \& Cheek, J. M. (1997). Assessing hypersensitive narcissism: A reexamination of Murray's Narcism scale. Journal of Research in Personality, 31, 588-599. https://doi.org/10.1006/jrpe. 1997.2204

Hyatt, C. S., Sleep, C. E., Lynam, D. R., Widiger, T. A., Campbell, W. K., \& Miller, J. D. (2018). Ratings of affective and interpersonal tendencies differ for grandiose and vulnerable narcissism: A replication and extension of Gore and Widiger (2016). Journal of Personality, 86(3), 422-434.

Kealy, D., \& Rasmussen, B. (2012). Veiled and vulnerable: The other side of grandiose narcissism. Clinical Social Work Journal, 40, 356-365. https://doi.org/10.1007/s10615-011-0370-1.

Kernis, M. H. (2003). Toward a conceptualization of optimal self-esteem. Psychological Inquiry, 14(1), 1-26. https://doi.org/10.1207/ S15327965PLI1401_01.

Kernis, M. H., \& Sun, C. (1994). Narcissism and reactions to interpersonal feedback. Journal of Research in Personality, 28, 4-13. https://doi.org/10.1006/jrpe.1994.1002.

Krusemark, E. A., Campbell, W. K., Crowe, M. L., \& Miller, J. D. (2018). Comparing self-report measures of grandiose narcissism, vulnerable narcissism, and narcissistic personality disorder in a male offender sample. Psychological Assessment, 30(7), 984-990.

Kubarych, T. S., Deary, I. J., \& Austin, E. J. (2004). The narcissistic personality inventory: Factor structure in a non-clinical sample. Personality and Individual Differences, 36(4), 857-872. https:// doi.org/10.1016/S0191-8869(03)00158-2.

Maxwell, K., Donnellan, M. B., Hopwood, C. J., \& Ackerman, R. A. (2011). The two faces of narcissus? An empirical comparison of the narcissistic personality inventory and the pathological narcissism inventory. Personality and Individual Differences, 50, 577-582. https://doi.org/10.1016/j.paid.2010.11.031.

Miller, J. D., Gentile, B., Carter, N. T., Crowe, M., Hoffman, B. J., \& Campbell, W. K. (2018). A comparison of the nomological networks associated with forced-choice and likert formats of the narcissistic personality inventory. Journal of Personality Assessment, 100(3), 259-267.

Morf, C. C., \& Rhodewalt, F. (2001). Unraveling the paradoxes of narcissism: A dynamic self-regulatory processing model. Psychological Inquiry, 12, 177-196. https://doi.org/10.1207/ S15327965PLI1204 1.

Muthén, L. K., \& Muthén, B. O. (1998-2015). Mplus User's Guide. CA: Los Angeles.

Oláh, A. (2012). A megküzdés szívárványszínei: a stresszkezeléstől a boldogság növeléséig [Colorful coping: from stress management to increasing happiness]. In M. Fülöp \& É. Szabó (Eds.), A pszichológia, mint társadalomtudomány [Psychology as a social science]. [Hungarian] Budapest: ELTE Eötvös Kiadó.

Pincus, A. L., Ansell, E. B., Pimentel, C. A., Cain, N. M., Wright, A. G., \& Levy, K. N. (2009). Initial construction and validation of the pathological narcissism inventory. Psychological Assessment, 21(3), 365-379. 
Pincus, A. L., \& Lukowitsky, M. R. (2010). Pathological narcissism and narcissistic personality disorder. Annual Review of Clinical Psychology, 6, 421-446. https://doi.org/10.1146/annurev.clinpsy. 121208.131215.

Pryor, L. R., Miller, J. D., \& Gaughan, E. T. (2008). A comparison of the psychological entitlement scale and the narcissistic personality Inventory's entitlement scale: Relations with general personality traits and personality disorders. Journal of Personality Assessment, 90(5), 517-520.

Raskin, R., \& Terry, H. (1988). A principle-components analysis of the narcissistic personality inventory and further evidence of its construct validity. Journal of Personality and Social Psychology, 54(5), 890-902. https://doi.org/10.1037/0022-3514.54.5.890.

Reise, S. P. (2012). The rediscovery of bifactor measurement models. Multivariate Behavioral Research, 47(5), 667-696. https://doi.org/ 10.1080/00273171.2012.715555.

Reise, S. P., Bonifay, W. E., \& Haviland, M. G. (2013). Scoring and modeling psychological measures in the presence of multidimensionality. Journal of Personality Assessment, 95(2), 129-140. https://doi.org/10.1080/00223891.2012.725437.

Reise, S. P., Moore, T. M., \& Haviland, M. G. (2010). Bifactor models and rotations: Exploring the extent to which multidimensional data yield univocal scale scores. Journal of Personality Assessment, 92(6), 544-559. https://doi.org/10.1080/00223891.2010.496477.

Rhodewalt, F., \& Peterson, B. (2009). Narcissism. In M. R. Leary \& R. H. Hoyle (Eds.), Handbook of individual differences in social behavior (pp. 547-560). New York, NY, US: Guilford Press.

Rodriguez, A., Reise, S. P., \& Haviland, M. G. (2016). Evaluating bifactor models: Calculating and interpreting statistical indices. Psychological Methods, 21(2), 137-150. https://doi.org/10.1037/ met0000045.

Ronningstan, E. (2013). Fear and decision-making in narcissistic personality disorder-A link between psychoanalysis and neuroscience. Dialogues in Clinical Neuroscience, 15(2), 191-201.

Rose, P. (2002). The happy and unhappy faces of narcissism. Personality and Individual Differences, 33(3), 379-391. https://doi.org/10. 1016/S0191-8869(01)00162-3.

Rosenberg, M. (1965). Society and the Adolescent Self-Image. In Society and the adolescent self-image. Princeton, NJ: Princeton University Press. https://doi.org/10.2307/2575639.

Rosenthal, S. A., Hooley, J. M., \& Steshenko, Y. (2007). Distinguishing grandiosity from self-esteem: Development of the Narcissistic Grandiosity Scale. Manuscript in preparation.

Ryff, C. D., \& Keyes, C. L. M. (1995). The structure of psychological well-being revisited. Journal of Personality and Social Psychology, 69(4), 719-727. https://doi.org/10.1037/0022-3514.69.4.719.
Solan, R. (2015). The enigma of childhood: the profound impact of the first years of life on adults as couples and parents. In Enigma of childhood: The profound impact of the first years of life on adults as couples and parents. London: Karnac Books. https://doi.org/10. 1080/13698036.2017.1302811.

Soto, C. J., \& John, O. P. (2017). The next big five inventory (BFI-2): Developing and assessing a hierarchical model with 15 facets to enhance bandwidth, fidelity, and predictive power. Journal of personality and social psychology, 113(1), 117.

Tabachnick, B. G., \& Fidell, L. S. (2014). Using Multivariate Statistics (6th ed.). Harlow: Pearson.

Ten Berge, J. M., \& Sočan, G. (2004). The greatest lower bound to the reliability of a test and the hypothesis of unidimensionality. Psychometrika, 69(4), 613-625. https://doi.org/10.1007/ BF02289858.

Twenge, J. M., Konrath, S., Foster, J. D., Keith Campbell, W., \& Bushman, B. J. (2008). Egos inflating over time: A cross-temporal meta-analysis of the narcissistic personality inventory. Journal of Personality, 76(4), 875-902. https://doi.org/10.1111/j.1467-6494. 2008.00507.x.

Urbán, R., Szigeti, R., Kökönyei, G., \& Demetrovics, Z. (2014). Global self-esteem and method effects: Competing factor structures, longitudinal invariance, and response styles in adolescents. Behavior Research Methods, 46(2), 488-498. https://doi.org/10.3758/ s13428-013-0391-5.

Wetzel, E., Roberts, B. W., Fraley, R. C., \& Brown, A. (2016). Equivalence of narcissistic personality inventory constructs and correlates across scoring approaches and response formats. Journal of Research in Personality, 61, 87-98. https://doi.org/10.1016/j.jrp. 2015.12.002.

Wink, P. (1996). Narcissism. In G. C. Costello (Ed.), Personality characteristics of the personality disorders (pp. 146-172). New York, NY: John Wiley and Sons.

World Economic Forum. (2017). Global Gender Gap Report 2017. Geneva: World Economic Forum. Available at: http://www3. weforum.org/docs/WEF GGGR 2017.pdf .

Zeigler-Hill, V., Clark, C. B., \& Pickard, J. D. (2008). Narcissistic subtypes and contingent self-esteem: Do all narcissists base their selfesteem on the same domains? Journal of Personality, 76(4), 753774. https://doi.org/10.1111/j.1467-6494.2008.00503.x.

Zuckerman, M., \& O'Loughlin, R. E. (2009). Narcissism and well-being: A longitudinal perspective. European Journal of Social Psychology, 39(6), 957-972. https://doi.org/10.1002/ejsp.594.

Publisher's note Springer Nature remains neutral with regard to jurisdictional claims in published maps and institutional affiliations. 